\title{
Aprendizagem e inclusão em espaço de educação não formal: relato de experiência
}

\section{Learning and inclusion in space of non-formal education: experience report}

\author{
Talita Silva Perussi Vasconcellos \\ Doutoranda em Educação Escolar \\ Universidade Estadual Paulista - UNESP. \\ Araraquara, SP - Brasil. \\ tallita.perussi@gmail.com \\ Rosimeire Maria Orlando \\ Pós Doutorado \\ Universidade Federal de São Carlos - UFSCAR. \\ São Carlos, SP - Brasil. \\ meire_orlando@ufscar.br
}

Resumo: O presente estudo busca apresentar uma experiência de inclusão socioeducacional realizada em um ambiente de ensino não formal por intermédio da metodologia de projetos. A experiência teve como objetivo elaborar, desenvolver e expor um projeto sobre a China, empenhando-se em trabalhar as múltiplas potencialidades. Caracterizou-se como estudo de caso, de cunho qualitativo, e utilizou a metodologia de projetos. Transcorreu durante um semestre em uma Organização da Sociedade Civil do interior paulista, que atende meninas crianças e adolescentes em situação de vulnerabilidade. Foram selecionadas meninas entre 8 e 12 anos, dentre elas, uma com Paralisia Cerebral. Durante os encontros, cada grupo pesquisou uma determinada curiosidade acerca do país mencionado e em todo o processo as participantes tiveram oportunidades de escolhas sobre seu interesse a respeito da temática. A experiência foi enriquecedora para todas, inclusive para a menina com Paralisia Cerebral, que participou de todo o decurso.

Palavras chave: educação especial; educação não formal; paralisia cerebral; metodologia de projetos.

Abstract: This experience report seeks to present an experience of socio-educational inclusion carried out in a non-formal teaching environment through the project methodology. The experience aimed to elaborate, develop and exhibit a project about China, striving to work on its multiple potentials. It was characterized as a case study, of a qualitative nature, and used the project methodology for its realization. It took place for a semester at a Civil Society Organization in the interior of São Paulo that assists girls, children and adolescents in vulnerable situations. Girls between 8 and 12 years old were selected, among them, one with Cerebral Palsy. Based on the interest of the participants, during the meetings, each group researched a certain curiosity about the mentioned country. Throughout the process, the participants had opportunities to make choices about their interest in the subject. The experience was enriching for all, including the girl with Cerebral Palsy who participated throughout the course.

Key-words: special education; non-formal education; cerebral palsy; project methodology.

Cite como

(ABNT NBR 6023:2018)

VASCONCELLOS, Talita Silva Perussi; ORLANDO, Rosimeire Maria. Aprendizagem e inclusão em espaço de educação não formal: relato de experiência. Dialogia, São Paulo, n. 39, p. 1-12, e20209, set./dez. 2021. Disponível em: https://doi.org/10.5585/39.2021.20209.

American Psychological Association (APA)

Vasconcellos, T. S. P., \& Orlando, R. M. (2021, set./dez.) Aprendizagem e inclusão em espaço de educação não formal: relato de experiência. Dialogia, São Paulo, 39, p. 1-12, e20209. https://doi.org/10.5585/39.2021.20209. 


\section{Introdução}

Este relato tem como objetivo apresentar uma experiência de inclusão socioeducacional em um ambiente de educação não formal por intermédio da metodologia de projetos.

Partindo do pressuposto que o meio influencia o desenvolvimento e a aprendizagem, não se pode negar a relação entre o desenvolvimento humano e o ambiente, sendo a criança e o ambiente influenciados mutuamente (RAPOPORT; SARMENTO, 2009). Logo, crianças que crescem em contextos desfavoráveis, presenciam e sofrem práticas violentas em família e recebem pouco estímulo por parte dos pais, tendem a ter prejuízos desenvolvimentais e serem influenciadas pelas mediações negativas a que foram submetidas (SILVA, 2009).

No que se refere à aprendizagem, sabe-se que seu início ocorre antes mesmo do ingresso da criança na escola havendo ligação entre aprendizagem e desenvolvimento (RAPOPOR; SARMENTO, 2009). Ainda, entende-se a mediação como a relação do homem com o mundo e com seus pares, portanto, essa mediação gera aprendizagem e desenvolvimento, acarretando na progressão das funções psicológicas superiores (VYGOTSKY, 1998).

Considerando que a aprendizagem dar-se-á por meio da mediação com o outro, destaca-se a importância de estar em um ambiente em que seja favorecida, como ponte para tal, adultos capazes e dispostos a estimular o potencial destas crianças (SILVA,2009). É inegável considerar que as vivências destas crianças possam afetar, de alguma forma, sua vida escolar (CAVALCANTI, 2005).

De acordo com Ferreira e Marturano (2002), as “crianças provenientes de famílias que vivem com dificuldades econômicas e habitam em comunidades vulneráveis, tendem a apresentar mais problemas de desempenho escolar e de comportamento" (p.39). O fato de muitas crianças estarem distantes de formas de estimulação intelectual, que poderiam lhes despertar interesse e curiosidade, pode acarretar altas taxas de problemas e de fracasso escolar, principalmente em bairros pobres (BEE, 1997).

Certo é que um dos objetivos fundamentais da República Federativa do Brasil é a redução das desigualdades sociais (BRASIL,1988) e que a igualdade de todos prevista no caput do artigo $5^{\circ}$ da Constituição ((BRASIL,1988) nasce ao lado da obrigatoriedade da redução das desigualdades e a vedação de discriminação, a saber, as que dizem respeito à raça, cor, sexo, idioma, religião, opinião política ou outra, origem nacional, posição econômica e nascimento, bem como "qualquer outra condição", afastando-se qualquer tentativa de discriminar por outros critérios, observa-se que os direitos se fazem acompanhar, necessariamente, de garantias. 
É desafiador que conquistas de direito internacional, em favor da proteção do ser humano, venham projetar-se no direito constitucional, enriquecendo-o e demonstrando que a busca de proteção cada vez mais eficaz da pessoa humana encontra guarida nas raízes do pensamento tanto internacionalista como constitucionalista.

Com referência aos direitos fundamentais alusivos às crianças e aos adolescentes presentes, além da Constituição Federal (BRASIL, 1988), no Estatuto da Criança e do Adolescente (BRASIL, 1994) há que se destacar que a criança e o adolescente gozam de todos os direitos fundamentais inerentes à pessoa humana, sendo garantido todas as oportunidades e facilidades, a fim de lhes facultar o desenvolvimento físico, mental, moral, espiritual e social, em condições de liberdade e de dignidade.

No que concerne os direitos e garantias expostos, destaca-se que a palavra vulnerável se origina do verbo latim vulnerare, que significa ferir, penetrar. Logo, observa-se que a criança em vulnerabilidade social é aquela privada de seus direitos. Nesta direção, Oliveira (1995) aponta que os grupos sociais vulneráveis poderiam ser definidos como pessoas em algum nível de pobreza.

Buscando atender a população em vulnerabilidade social, a educação não formal ocorre em ambientes e situações interativos construídos coletivamente, tendo como objetivo uma intencionalidade na ação, no ato de participar, de aprender e de transmitir ou trocar saberes. Tal modalidade aborda a educação como promotora de formas de inclusão social, formas estas que, proporcionam acesso aos direitos de cidadania, que resgatam alguns ideais já esquecidos pela humanidade, como o de civilidade, tolerância e respeito ao outro (GOHN, 2006).

Por sua vez, os Projetos Educacionais presentes na educação não formal baseiam-se na definição de inclusão que devem privilegiar as ações coletivas, com sentido e significado para o grupo participante. Contrariando as concepções relativas às formas que buscam, simplesmente, integrar indivíduos em situação de vulnerabilidade social em programas sociais compensatórios capacitando os indivíduos a se tornarem cidadãos do mundo, no mundo. Sua finalidade é abrir janelas de conhecimento sobre o mundo que circunda os indivíduos e suas relações sociais (GOHN, 2006).

Ressalta-se que o conhecimento da realidade e da cultura do grupo de educandos é primordial no trabalho da Educação Popular e da Educação não formal, pois, seus métodos podem ser concretizados a partir da problematização das relações estabelecidas e do cotidiano dos aprendizes. Este caminho metodológico leva em conta a premissa de que a criança e o adolescente, enquanto educandos, não estão desconectados da realidade, ou seja, não se configurando a dicotomia homem-mundo. 
No mesmo sentido de direitos, o contexto legislativo nacional e internacional tem sido marcado por grandes reformas político-administrativas na área da deficiência. Tais reformas são consequência de movimentos sociais e mudanças socioculturais, principalmente, em relação a princípio e garantias de igualdade (BRASIL,1988). Em consequência do presente direito constitucional, o Estado adota o conceito de deficiência, reconhecendo as pessoas com deficiência como aquelas que possuem impedimentos de natureza física, intelectual ou sensorial, que, em interação com diversas barreiras (arquitetônica, transporte, pedagógica, atitudinal, dentre outras), podem ter obstruída sua participação plena e efetiva na sociedade (BRASIL, 2008).

Torna-se perninente, neste ponto, apontar o Decreto $n^{\circ} 5.296$ de 2 de dezembro de 2004, que o define a deficiência física como:

\begin{abstract}
Alteração completa ou parcial de um ou mais segmentos do corpo humano, acarretando o comprometimento da função física, apresentando-se sob a forma de paraplegia, paraparesia, monoplegia, monoparesia, tetraplegia, tetraparesia, triplegia, triparesia, hemiplegia, hemiparesia, ostomia, amputação ou ausência de membro, Paralisia Cerebral, nanismo, membros com deformidade congênita ou adquirida, exceto as deformidades estéticas e as que não produzam dificuldades para o desempenho de funções (BRASIL, 2004, p.1).
\end{abstract}

No que se refere ao direito das pessoas com deficiência, destaca-se a importância de serem ofertadas oportunidades para o desenvolvimento das pessoas com deficiência física e, nesta direção, evidencia-se a metodologia de Projetos.

Para Dewey (1967), a aquisição isolada de saber intelectual gera um ensino descontextualizado que perde o sentido para o educando. Nesse encontro, temos queo trabalho com a metodologia de projetos é baseado na problematização. O aprendiz deve ser envolvido no problema, ele tem que investigar, registrar dados, formular hipóteses, de modo queo educador deixa de ser o único responsável pela aprendizagem e o aprendiz torna-se pesquisador (HERNÁNDEZ E VENTURA, 1998).

Abordando especificamente os Projetos de Trabalho, os autores Hernández e Ventura (1998) elencam os seguintes aspectos:

a) A escolha do tema a partir das experiências anteriores dos aprendizes. Esse tema pode fazer parte do "currículo oficial", de uma experiência comum, de um fato da atualidade, de um problema proposto pelo educador. Ressalta-se que não existem temas que não possam ser abordados dentro dos projetos;

b) A atividade do educador, após estabelecido o tema e levantadas as hipóteses a respeito dele, deverá ser de especificar o fio condutor que fará com que o projeto ultrapasse a aquisição de informações e se torne instrumento para a construção de novos conhecimentos. Ele deve destacar 
os conteúdos conceituais e procedimentais possíveis de serem desenvolvidos, indicar fontes de informação, criar um clima de envolvimento e interesse do grupo e planejar etapas do projeto;

c) A atividade dos aprendizes, após a escolha do projeto, é a elaboração de um roteiro inicial de investigação da classe; busca de informações que complementem e ampliem aquelas apresentadas inicialmente na proposta; tratamento dessas informações, uma vez que elas possibilitam visões da realidade, síntese, estabelecimento de relações e novos questionamentos; realização da avaliação de todo o processo interno e externo de elaboração do projeto;

d) Na busca das fontes de informação, parte-se do pressuposto de que o aprender é um ato comunicativo. O educador assumirá, então, o papel de facilitador desse processo, na medida em que, partindo de sua capacidade, transformará as referências informativas em materiais de aprendizagem, com uma intenção crítica e reflexiva. A autonomia dos aprendizes é favorecida, mais do que pela busca das fontes de informação, pelo diálogo estabelecido entre educador e aprendiz para estabelecer comparações, inferências e relações, o que ajuda a dar sentido à aprendizagem que se pretende com os projetos.

Frisa-se que a função do projeto é favorecer a criação de estratégias de organização dos conhecimentos escolares em relação a: 1) o tratamento da informação e; 2) a relação entre os diferentes conteúdos em torno de problemas ou hipóteses que facilitem aos educandos/as a construção de seus conhecimentos, a transformação procedente dos diferentes saberes disciplinares em conhecimento próprio (HERNANDEZ \& VENTURA, 1998).

Nesse sentido, ao trabalhar com projetos, é possível desenvolver competências, propor tarefas complexas e desafios que estimulem os educandos/as a mobilizar seus conhecimentos e completá-los. A experiência com projetos em ambientes de ensino tem se mostrado eficiente no desenvolvimento, no trabalho com os conteúdos atitudinais e procedimentais, além de permitir que o conhecimento passe a ser tratado como uma "rede de significados" que, contrapondo o olhar cartesiano, possui múltiplos ou nenhum centro, o que depende do interesse dos educadores e aprendizes sobre o tema em estudo (MACHADO,2004).

Diante disso, conforme mencionamos, o presente relato de experiência tem o objetivo de apresentar uma experiência de inclusão socioeducacional realizada em um ambiente de ensino não formal por meio da metodologia de projetos.

\section{Metodologia}

A OSC tem como objetivo contribuir para o desenvolvimento integral de crianças e adolescentes, mediante a participação e a convivência em espaços e atividades - culturais, 
educacionais e sociais - complementares à família, à escola e à comunidade. Sendo o principal objetivo propiciar às meninas, crianças e adolescentes, condições, ambiente e espaços de aprendizagem para a reflexão e o protagonismo, visando seu desenvolvimento integral, além da convivência e fortalecimento de vínculos para adolescentes vítimas de violência e em situação de vulnerabilidade.

Durante um semestre foi desenvolvido um projeto com uma turma da organização, que teve como tema a China. As participantes foram 19 meninas de faixa etária entre 7 e 12 anos, divididas em duas turmas, sendo que uma das crianças possuía Paralisia Cerebral. No quadro 1 temos a apresentação das participantes, cabe indicar que seus nomes são fictícios.

Quadro 1 - Caracterização dos participantes

\begin{tabular}{c|c|c}
\hline Nome de Identificação & Idade \\
\hline Ana & 8 & $3^{\circ}$ \\
\hline Bruna & 12 & $6^{\circ}$ \\
\hline Diana & 8 & $3^{\circ}$ \\
\hline Fabricia & 7 & $2^{\circ}$ \\
\hline Isabel & 9 & $3^{\circ}$ \\
\hline Isabella & 9 & $4^{\circ}$ \\
\hline Jamilli & 12 & $6^{\circ}$ \\
\hline Elza & 7 & $1^{\circ}$ \\
\hline Joice & 10 & $4^{\circ}$ \\
\hline Nala & 8 & $3^{\circ}$ \\
\hline Fiona & 8 & $3^{\circ}$ \\
\hline Diana & 9 & $3^{\circ}$ \\
\hline Isabel & 8 & $3^{\circ}$ \\
\hline Laura & 8 & $3^{\circ}$ \\
\hline Camila & 11 & $5^{\circ}$ \\
\hline Cristiana & 12 & $6^{\circ}$ \\
\hline Amanda & 12 & $6^{\circ}$ \\
\hline Thalita & 12 & $6^{\circ}$ \\
\hline Alice & 8 & $3^{\circ}$ \\
\hline
\end{tabular}

Fonte: Elaboração própria.

\section{Procedimentos}

Primeiramente, em reuniões entre os educadores da instituição e coordenadora, as turmas foram divididas, de modo que cada educador ficou responsável por turmas diferentes dentro do projeto a ser desenvolvido e apresentado na Feira do Conhecimento. O tema específico poderia ser livre e de interesse de cada turma.

Com a divisão por turmas, iniciou-se o trabalho, com base na metodologia de projetos, seguindo as etapas divididas:

1. Sondagem de interesses: nessa etapa, utilizando dinâmicas, observou- se o tema de interesse das 
meninas para ser estudado.

2. Delineamento de objetivos de ensino: sendo definido o objetivo geral de pesquisa, as etapas da pesquisa foram traçadas com as meninas, bem como seus desdobramentos.

3. Planejamento: nesta etapa, a educadora, juntamente com as meninas, definiu as etapas para apresentar o trabalho final.

4. Etapas de execução: assistir filme sobre o tema; separar grupos para temas específicos dentro do tema geral escolhido; pesquisar no laboratório de informática sobre o tema; confeccionar cartazes; ensaiar a apresentação; apresentação interna dna feira de conhecimentos.

5. Avaliação final: a educadora e as crianças observaram os pontos positivos e os que necessitariam de melhoramento do trabalho feito.

\section{Resultados e discussão}

\section{Sondagem de interesses}

Esta primeira etapa teve como objetivo observar a compreensão e entendimento que as meninas mantiveram entre si em seus diálogos. Em outras palavras, observar a comunicação, expressão e o posicionamento delas em reconhecer-se enquanto sujeito dentro do espaço em que estavam inseridas e de estabelecer relações com o mundo que as cercava. No quadro 2, encontramse as ações, recursos e áreas trabalhadas.

Quadro 2 - Atividade de sondagem

\begin{tabular}{|l|l|l|l|}
\hline \multicolumn{1}{|c|}{$\begin{array}{c}\text { Ações da } \\
\text { educadora }\end{array}$} & \multicolumn{1}{|c|}{$\begin{array}{c}\text { Ações das } \\
\text { participantes }\end{array}$} & $\begin{array}{c}\text { Recursos } \\
\text { utilizados }\end{array}$ & $\begin{array}{c}\text { Áreas } \\
\text { trabalhadas }\end{array}$ \\
\hline $\begin{array}{l}\text { 1. A educadora pediu para as } \\
\text { crianças sentarem em roda }\end{array}$ & $\begin{array}{l}\text { As participantes se } \\
\text { sentaram no chão junto à } \\
\text { pesquisadora. }\end{array}$ & $\begin{array}{l}\text { Próprias participantes } \\
\text { Poção espacial (lateralidade) }\end{array}$ & Comunicação e expressão \\
\hline $\begin{array}{l}\text { 2. A educadora } \\
\text { pegou um microfone e pediu } \\
\text { as as crianças responderem } \\
\text { as perguntas feitas pelas } \\
\text { pesquisas (sobre quem ela é e }\end{array}$ & $\begin{array}{l}\text { Compreender e entender } \\
\text { a si mesmo para } \\
\text { responder as perguntas }\end{array}$ & $\begin{array}{l}\text { Microfone de brincadeira. } \\
\text { Roteiro de entrevista: } \\
\text { O que você mais gosta no } \\
\text { mundo todo? } \\
\text { O que você gostaria de } \\
\text { aprender? } \\
\text { Como você gostaria de } \\
\text { aprender? }\end{array}$ & \\
\hline
\end{tabular}

Fonte: Elaboração Própria

A educadora sentou-se em frente às meninas e, com um estojo (que ludicamente fingiu ser um microfone), as entrevistou. Durante toda a entrevista as meninas sorriram e mostraram interesse pela "brincadeira". Todas responderam com entusiasmo que queriam aprender sobre 
pessoas diferentes delas, uma hipótese pode ser o fato da realização da Copa do Mundo de futebol e a apresentação pela mídia televisiva de outros países e culturas. A educadora, então, mediou as perguntas pedindo para elas especificarem sobre o que gostariam de aprender. Houve a indicação de vários países como: China, Estados Unidos, Rússia e Japão. A partir desta indicação, houve um sorteio, sendo que o país contemplado foi a China.

Em relação à forma que desejavam aprender as crianças responderam: "brincando", "com computador", “com filme”, “com histórias”, entre outras respostas semelhantes.

\section{Delineamento de objetivos de ensino, planejamento e divisão de etapas}

Buscando partir do interesse das crianças iniciou-se a elaboração das etapas de ensino, visto que, quando o aluno percebe que textos estão ligados a assuntos que gosta, sente-se estimulado, pois entende que a língua escrita tem significação em sua realidade (DORO, 2010).

Quadro 3 - Planejamento levantamento de interesses

\begin{tabular}{|l|l|l|l|}
\hline \multicolumn{1}{|c|}{ Ações da educadora } & Ações das participantes & Recursos utilizados & Áreas trabalhadas \\
\hline $\begin{array}{l}\text { 1. Conversa com as participantes } \\
\text { sobre futura elaboração do } \\
\text { planejamento de } \\
\text { ensino }\end{array}$ & $\begin{array}{l}\text { Sentarem em círculo e } \\
\text { participarem da discussão }\end{array}$ & Próprias participantes & $\begin{array}{l}\text { Comunicação e } \\
\text { expressão }\end{array}$ \\
\cline { 1 - 2 } $\begin{array}{l}\text { 2. Pedir que falassem sobre como } \\
\text { queriam } \\
\text { aprender. }\end{array}$ & $\begin{array}{l}\text { Responderem à } \\
\text { pesquisadora }\end{array}$ & Próprias crianças & \\
\hline
\end{tabular}

Fonte: Elaboração própria.

Durante o momento de verificação, a educadora pediu às crianças que sentassem em círculo e falassem sobre o que gostam e sobre o que não gostam. Ao observar que todas as crianças mencionaram "trabalho em cartolina", "sala de informática”, "apresentação", "cada um pesquisar uma coisa" e "filme", a partir disso, a educadora mediou a criação das etapas do projeto, que abrangesse tudo que foi exposto, e escreveu em conjunto com elas em um cartaz:

- Assistir filme sobre o tema;

- Separação de grupos para temas específicos;

- Pesquisa no laboratório de informática sobre o tema;

- Confecção de cartazes e Apresentação.

Partindo da premissa que filmes de animação, em especial longa metragens, trabalham a fantasia e a subjetividade em crianças fazendo-as se transportarem para esse novo universo de cores, efeitos e sons (PINEL, 2017), a educadora escolheu o filme de animação Mulan, de 
origem norte americana, do ano de 1998, da Walt Disney Animation Studios, baseado na lenda chinesa de Hua Mulan.

A lenda conta a história de uma heroína que, disfarçada de guerreiro, se une a um exército exclusivamente masculino. A obra foi composta no século VII, durante a maior parte da qual a dinastia Tang (618-907) governou a China e foi adaptada para a animação, que em todo o decorrer trabalha os tradições chinesas, o empoderamento e a igualdade de direitos femininos. Segundo Silva e Gomes (2009) entende-se que as animações podem servir como ferramentas que auxiliam no processo de educação, que inclui a própria formação de identidade, à medida que tais filmes abordam muito mais do que preconceito e discussões sociais, mas representam o pensamento e a forma do agir social.

O filme foi passado em pequenas partes, $15 \mathrm{~min}$ em cada aula, sendo mediado pela educadora. A educadora trazia pesquisas e imagens reais do que foi relatado na animação: Muralha da China, comida chinesa, roupas típicas femininas e masculinas, etc. Ao todo, foram necessárias seis aulas para o filme ser assistido por completo.

Pediu-se, então, para que as crianças se dividissem em grupos para realização do trabalho, ressalta-se que a aluna com Paralisia Cerebral, participou ativamente de todo o processo escolhendo seu grupo por afinidade e não necessitando de adaptações.

Os grupos, então, escolheram seus temas: G1- mulher na China; G2- animais na China; G3 Lenda da Mulan; G-4 comida da chinesa.

Nas próximas quatro aulas, as meninas foram para a sala de informática. Mediou-se a pesquisa de imagens e textos sobre o tema escolhido. No momento em que a aluna com Paralisia Cerebral desejava digitar algo no teclado do computador, as demais meninas do grupo colocavam o teclado em seu colo, o que promoveu acesso ao uso da tecnologia.

Durante a fase de pesquisa as crianças de deparavam com outros temas sobre o país em foco e perguntavam para a pesquisadora se podiam se separar do grupo e pesquisar outro tema. A pesquisadora compreendeu essa experiência de trabalho com projetos como enriquecedora, pois, a curiosidade da temática partiu do próprio aprendiz. Uma dessas crianças que se interessou por outra temática foi a aprendiz com Paralisia Cerebral. Ela se interessou pela árvore Bambu, típica da China e muito comentada na animação assistida.

Os cartazes foram confeccionados de acordo com as escolhas de imagens e textos dos grupos, a educadora mediava a leitura e interpretações de textos mais complexos. 
Após a confecção dos cartazes, houve a apresentação interna da Feira de Conhecimento, com a participação de todas as meninas que frequentam a instituição.

Em todo o processo elas tiveram autonomia para a seleção do que acreditavam ser o mais importante sobre a temática para exposição.

Ressalta-se, novamente, que em todo o processo a aprendiz com Paralisia Cerebral, participou ativamente do processo, bem como, todas as crianças. Todas as participantes mostraram-se seguras do que diziam, visto que participaram de seu próprio aprendizado de maneira ativa e autônoma durante todo o processo.

À vista disso, enfatiza-se que o grande desafio da inclusão é construir e pôr em prática um aprendizado que alcance a todos, porém, capaz de atender os aprendizes cujas situações pessoais e características de aprendizagem requeiram uma pedagogia diferenciada, visto que é necessário respeitar a heterogeneidade e responder às diversas necessidades educativas, considerando que cada um possui particularidades no aprendizado (MENDES, 2006).

\section{Considerações}

O presente relato de experiência apresentou uma experiência de inclusão em um ambiente de ensino não formal por meio da metodologia de projetos. Foi realizado em seis meses com 19 participantes de faixa etária entre 8 e 12 anos e uma delas com Paralisia Cerebral.

Percebeu-se que, em todo o processo, o foco não consistiu nas dificuldades ou limitações dos aprendizes e sim em seus interesses, potencialidades e autonomia.

A partir da experiência de ensino, observou-se que os aprendizes demonstraram motivação durante o aprendizado de temas de interesse, utilizando percursos diversos. Apenas pequenas adaptações foram feitas para o acesso ao conhecimento da aprendiz com Paralisia Cerebral, por meio de tecnologia. Foi possível notar seu engajamento durante todo o processo de desenvolvimento do Projeto.

Os resultados de tal experiência indicam a importância de novos estudos que tenham como objetivos conhecer e trabalhar a inclusão do aprendiz com e sem deficiência em ambientes de ensino não formais, para que de fato a inclusão exista em todos os setores educacionais brasileiros.

\section{Referências}

BRASIL. Constituição da República Federativa do Brasil. Brasília, DF: Centro Gráfico, 1988.

BRASIL. Estatuto da criança e do adolescente, 1994. 
BRASIL. A inclusão escolar de alunos com necessidades educacionais especiais: DEFICIÊNCIA FÍSICA, 2004.

BRASIL. Nacional de Educação Especial na Perspectiva da Educação Inclusiva. Brasilia, 2008.

DEWEY, J. Vida e Educação. 6. ed. São Paulo: Melhoramentos, 1967.

DORO, F. G. Práticas de Leitura e Escrita na Alfabetização. (UFJF), v. 2, p. 1- 8, 2010. Disponível em: http://www.ufff.br/virtu/ files/2010/04/artigo-2a11.pdf

GOHN, M. G. O Ato investigativo na produção do conhecimento: Questões Metodológicas. São Paulo, UNINOVE, 2006.

HERNÁNDEZ, F; VENTURA, M. A organização do curriculo por projetos de trabalho: o conbecimento é um caleidoscópio. Porto Alegre: Artes Médicas, 1998.

MACHADO, Nilson José. Educação: projetos e valores. 5. ed. São Paulo: Escrituras, 2004.

MENDES, E. G. A radicalização do debate sobre inclusão escolar no Brasil.

Revista Brasileira de Educaşão, v. 11, n. 33, Set. /Dez. 2006.

OLIVEIRA, F. A questão do Estado: vulnerabilidade social e carência de direitos. In: Subsídios à Conferência Nacional de Assistência Social, 1. Brasília: CNAS, out. 1995.

PINEL, H. O céu eu vou tocar: um estudo sobre deficiência física nos desenhos animados Valente e Como Treinar O Seu Dragão. Educare, v. 1, 2017.

SHMIDT, D. D. Introdução à educação especial: Ensinar em tempos de inclusão. Porto Alegre: Artmed, 2008.

SILVA, T. C. R.; GOMES. A. C. F. A importância dos desenhos animados como representação ideológica: formação da identidade infantil. CESUMAR, São Paulo, jan. /jun., v.11, n.1, p 37-43, 2009.

YIN, R.K. Estudo de Caso: Planejamento e Métodos. Bookman: Porto Alegre, $2{ }^{\circ}$ Ed. 2001 